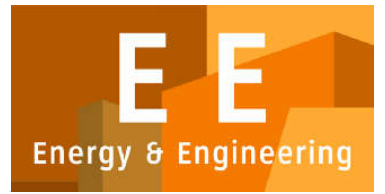

PAPER - OPEN ACCESS

\title{
Analisis Postur Kerja Untuk Mengurangi Tingkat Risiko Kerja Menggunakan Metode Rapid Office Strain Assessment (ROSA)
}

\author{
Author $\quad$ : Cut Ita Erliana dan Munadya Zaphira \\ DOI $\quad: 10.32734 /$ ee.v2i3.774 \\ Electronic ISSN $\quad: 2654-704 X$ \\ Print ISSN : :2654-7031
}

Volume 2 Issue 3 - 2019 TALENTA Conference Series: Energy \& Engineering (EE)

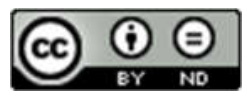

This work is licensed under a Creative Commons Attribution-NoDerivatives 4.0 International License.

Published under licence by TALENTA Publisher, Universitas Sumatera Utara

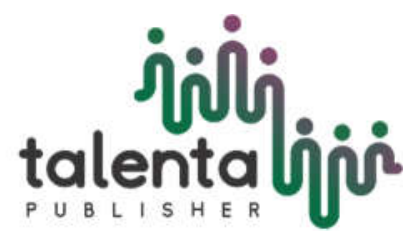




\section{jibli (and TALENTA Conference Series}

Available online at https://talentaconfseries.usu.ac.id

\title{
Analisis Postur Kerja Untuk Mengurangi Tingkat Risiko Kerja Menggunakan Metode Rapid Office Strain Assessment (ROSA)
}

\author{
Cut Ita Erliana* dan Munadya Zaphira \\ Jurusan Teknik Industri, Universitas Malikussaleh, Aceh Utara, Indonesia \\ cutitha@unimal.ac.id
}

\begin{abstract}
Abstrak
Frekuensi yang tinggi akan penggunaan komputer yang tidak mempertimbangkan sisi ergonomi dalam bekerja mengakibatkan adanya risiko yang dirasakan oleh pengguna. Dept. PSDM dan Dept. Personalia \& Benefit PT Pupuk Iskandar Muda merupakan departemen yang menggunakan komputer sebagai salah satu alat utama dalam bekerja. Keluhan yang dirasakan oleh pekerja pada Dept. PSDM dan Dept. Personalia \& Benefit dapat di minimalkan dengan cara mengetahui dan mengidentifikasi postur kerja pada pekerja dalam menggunakan komputer. Identifikasi tersebut digunakan untuk mengetahui kondisi pekerja dan mengetahui penyebab keluhan yang dirasakan oleh pekerja. Apabila kondisi postur kerja karyawan pada Dept. PSDM dan Dept. Personalia \& Benefit berisiko tinggi maka dapat dilakukan tindakan lanjutan dari hasil identifikasi postur kerja karyawan untuk meminimalkan risiko yang diderita oleh karyawan bersangkutan. Salah satu cabang ilmu ergonomi yang menyangkut tentang desain dan kenyamanan pada lingkungan perusahaan non pabrik adalan office ergonomics. Office ergonomics akan mengatur bagaimana posisi kerja yang benar pada pekerja pada saat bekerja dilingkungan perusahaan non pabrik. Rapid Office Strain Assessment (ROSA) adalah salah satu metode pada office ergonomics, dimana metode tersebut berupa penilaian yang dirancang untuk mengukur risiko postur kerja yang terkait dengan penggunaan komputer serta untuk menentukan tindakan atau perbaikan. Analisis postur kerja dengan metode Rapid Office Strain Assessment (ROSA) menunjukkan bahwa 10 karyawan yang menjadi sampel penelitian memiliki level beresiko dan perlu dilakukan perbaikan dalam waktu dekat. Perbaikan yang dapat dilakukan untuk mengurangi tingkat resiko yang dirasakan oleh karyawan yaitu dengan perbaikan fasilitas yang digunakan oleh karyawan yang sesuai dengan standar ergonomi pada dunia kerja, dan sosialisasi tentang ergonomi terutama diperkantoran terutama kepada karyawan agar karyawan dapat menggunakan fasilitas dengan maksimal.
\end{abstract}

Kata Kunci : Ergonomi, Postur Kerja, Office Ergonomic, Rapid Office Strain Assessment (ROSA)

\section{Pendahuluan}

Teknologi yang semakin canggih dapat memudahkan manusia dalam melakukan pekerjaan, salah satunya seperti kegunaan komputer yang memiliki peran sangat besar pada pekerjaan terutama di perusahaan. Frekuensi yang tinggi akan penggunaan komputer yang tidak mempertimbangkan sisi ergonomi dalam bekerja mengakibatkan adanya risiko yang dirasakan oleh pengguna. Pengguna akan merasakan kelelahan yang berlebihan seperti, sakit kepala, stress, ketegangan pada leher, punggung, lengan, bahu, nyeri otot, dan bagian yang berhubungan langsung dengan kerja komputer.

Keluhan akibat tingginya penggunaan komputer pada saat bekerja terjadi karena adanya masalah dengan peralatan atau fasilitas, tata letak tempat kerja, kondisi lingkungan kerja, atau kombinasi dari beberapa faktor tersebut. Pengaruh dari tata letak tempat kerja yang tidak tepat misalnya, memaksa seseorang untuk melakukan postur kerja yang tidak ergonomis.

Dept. PSDM dan Dept. Personalia \& Benefit PT Pupuk Iskandar Muda merupakan departemen yang menggunakan komputer sebagai salah satu alat utama dalam bekerja. Pada Dept. PSDM dan Dept. Personalia \& Benefit sembilan puluh lima persen karyawan menggunakan komputer sebagai alat bantu dalam bekerja. Rata-rata penggunaan 
komputer karyawan Dept. PSDM dan Dept. Personalia \& Benefit per hari adalah 8 jam kerja dan jika lembur menjadi 9-10 jam kerja.

Salah satu cabang ilmu ergonomi yang menyangkut tentang desain dan kenyamanan pada lingkungan perusahaan non pabrik adalan office ergonomics. Office ergonomics akan mengatur bagaimana posisi kerja yang benar pada pekerja pada saat bekerja dilingkungan perusahaan non pabrik. Aspek ergonomi di perusahaan non pabrik merupakan suatu hal yang sangat penting untuk diperhatikan dan diterapkan oleh perusahaan. Selain itu memperbaiki lingkungan kerja juga akan meningkatkan produktivitas kerja, meningkatkan sikap siap kerja karyawan, mengurangi adanya turnorver (pergantian) karyawan. Rapid Office Strain Assessment (ROSA) adalah salah satu metode pada office ergonomics, dimana metode tersebut berupa penilaian yang dirancang untuk mengukur risiko postur kerja yang terkait dengan penggunaan komputer serta untuk menentukan tindakan atau perbaikan.

Keluhan yang dirasakan oleh pekerja pada Dept. PSDM dan Dept. Personalia \& Benefit dapat di minimalkan dengan cara mengetahui dan mengidentifikasi postur kerja pada pekerja dalam menggunakan komputer. Identifikasi tersebut digunakan untuk mengetahui kondisi pekerja dan mengetahui penyebab keluhan yang dirasakan oleh pekerja. Apabila kondisi postur kerja karyawan pada Dept. PSDM dan Dept. Personalia \& Benefit berisiko tinggi maka dapat dilakukan tindakan lanjutan dari hasil identifikasi postur kerja karyawan untuk meminimalkan risiko yang diderita oleh karyawan bersangkutan.

\section{Landasan Teori}

\section{A. Ergonomi}

Kata ergonomi berasa dari bahasa Yunani, yaitu terdiri atas kata dasar "Ergos" yang berarti bekerja, dan "Nomos" yang artinya hukum alam, sehingga dapat didefinisikan sebagai studi tentang aspek-aspek manusia dan lingkungan kerjanya yang ditinjau secara antomi, fisiologi, engineering, manajemen dan desain/persancangan (Nurmianto, Eko. 1996). Pada dasarnya Ergonomi adalah suatu cabang ilmu yang sistematis untuk memanfaatkan informasi-informasi mengenai sifat, kemampuan, dan keterbatasan manusia untuk merancang suatu sistem kerja sehingga orang dapat hidup dan bekerja pada sistem itu dengan baik, yaitu untuk mencapai tujuan yang diinginkan melalui pekerjaan itu dengan efektif, aman, dan nyaman (Sutalaksana. 1979). Mc Cormick, dalam buku "Human Factor in Engineering and Design" memberikan pengertian ergonomi kedalam bagian-bagian berikut ini:

1. Fokus utama ergonomi berkaitan dengan pemikiran manusia dalam mendesain peralatan, fasilitas, dan lingkungan yang dibuat oleh manusia, yang digunakan dalam berbagai aspek kehidupannya.

2. Tujuan dari ergonomi dalam mendesain peralatan.

\section{B. Postur Kerja}

Menurut Merulla, 2010 bekerja merupakan suatu kegiatan manusia merubah keadaan-keadaan tertentu dari alam lingkungan yang ditujukan untuk mempertahankan dan memelihara kelangsungan hidupnya. Studi ergonomi yang kaitannya dengan kerja manusia dalam hal ini ditunjukkan untuk mengevaluasi dan merancang kembali tata cara kerja yang harus diaplikasikan, agar dapat memberikan peningkatan efektifitas dan efisiensi selain juga kenyamanan ataupun keamanan bagi manusia sebagai pekerjanya. Bila postur kerja yang digunakan pekerja salah atau tidak ergonomis, pekerja akan cepat lelah sehingga kosentrasi dan tingkat ketelitiannya menurun yang pada akhirnya menyebabkan turunnya produktivitas. Sikap kerja alamiah atau postur normal yaitu sikap atau postur dalam proses kerja yang sesuai dengan anatomi tubuh sehingga tidak terjadi pergeseran atau penekanan pada bagian penting tubuh seperti organ tubuh, syaraf, tendon, dan tulang sehingga keadaan menjadi relaks dan tidak menyebabkan muskuloskeletal serta sistem tubuh yang lain. Sikap kerja yang tidak alamiah adalah sikap kerja yang menyebabkan posisi bagian tubuh bergerak menjauhi posisi alamiah. Semakin jauh posisi tubuh jauh dari bagian gravitasi tubuh, semakin tinggi pula risiko terjadinya keluhan otot. Sikap kerja tidak alamiah ini umumnya disebabkan oleh sikap karakteristik tuntutan tugas, alat kerja dan stasiun kerja tidak sesuai dengan kemampuan dan keterbatasan pekerja (Anies, 2005).

\section{Dampak dari Postur Kerja yang Tidak Seimbang.}

Adapun dampak dari postur kerja yang tidak seimbang adalah keluhan muskuloskeletal atau suatu kondisi yang mengganggu fungsi sendi, ligamen, otot, saraf dan tendon serta tulang belakang. Keluhan ini biasanya di istilahkan dengan keluhan Musculoskeletal Disorders atau cedera pada sistem muskuloskeletal. Penyebab terjadinya keluhan 
muskuloskeletal adalah peregangan otot yang berlebihan seperti mengangkat beban dan aktivitas yang dilakukan secara berulang. Secara garis besar keluhan otot dapat dikelompokkan menjadi dua (Tarwaka, 2004), yaitu:

1. Keluhan Sementara

Keluhan ini merupakan keluhan otot yang terjadi pada saat otot menerima beban statis , namun demikian keluhan tersebut akan segera hilang apabila pembebanan dihentikan.

2. Keluhan Menetap

Keluhan yang besifat menetap meskipun pembebanan dihentikan, namun rasa sakit masih tetap berlanjut. Keluhan menetap yang sering dikeluhkan biasanya adalah otot rangka yang meliputi otot leher, bahu, lengan, jari, punggung, pinggang dan otot bagian bawah. Keluhan ini pada umumnya terjadi karena kontraksi otot yang berlebihan akibat pemberian beban kerja yang terlalu berat dengan durasi pembebanan yang panjang.

\section{Office Ergonomic}

Menurut Kroemar, 2001, Office ergonomics merupakan penerapan dari ilmu ergonomi meliputi keseluruhan lingkungan kerja dan alat kerja digunakan seperti perangkat komputer dan kursi. Penerapan ergonomi di perkantoran lebih fokus pada bahaya penggunaan komputer. Bahaya ditimbulkan pada saat bekerja di perkantoran juga dipengaruhi peralatan digunakan diantara lain adalah mouse, keyboard, monitor meja dan kursi komputer. Masing-masing dari peralatan tersebut memiliki ketentuan-ketentuan agar dalam kondisi ergonomis, sehingga pengguna dapat menggunakan dengan nyaman. Berikut ini penjelaskan persyaratan dari setiap peralatan kerja digunakan sehingga dapat termasuk peralatan kerja ergonomis (Ontario, 2004).

\section{E. Rapid Office Strain Assessment}

Rapid Office Strain Assessment (ROSA) adalah metode penilaian ergonomi untuk kantor dan pekerjaan yang berhubungan dengan komputer/administrasi. ROSA merupakan salah satu metode pada office ergonomics, dimana penilaiannya dirancang untuk mengukur risiko yang terkait dengan penggunaan komputer serta untuk menetapkan tingkat tindakan perubahan berdasarkan laporan dari ketidak nyamanan pekerja. Dalam metode ini penilaian dilakukan dengan menganalisa postur yang penilaian dilakukan dengan mengisi checklist, seperti penggunaan checklist pada REBA. Tujuan dari penilaian ergonomi ini adalah sebagai screening tools untuk mengidentifikasi prioritas pengendalian ergonomi di tempat kerja.

\section{Metodelogi Penelitian}

Berikut ini flowchart dari metodelogi penelitian yang akan kami laksanakan. 


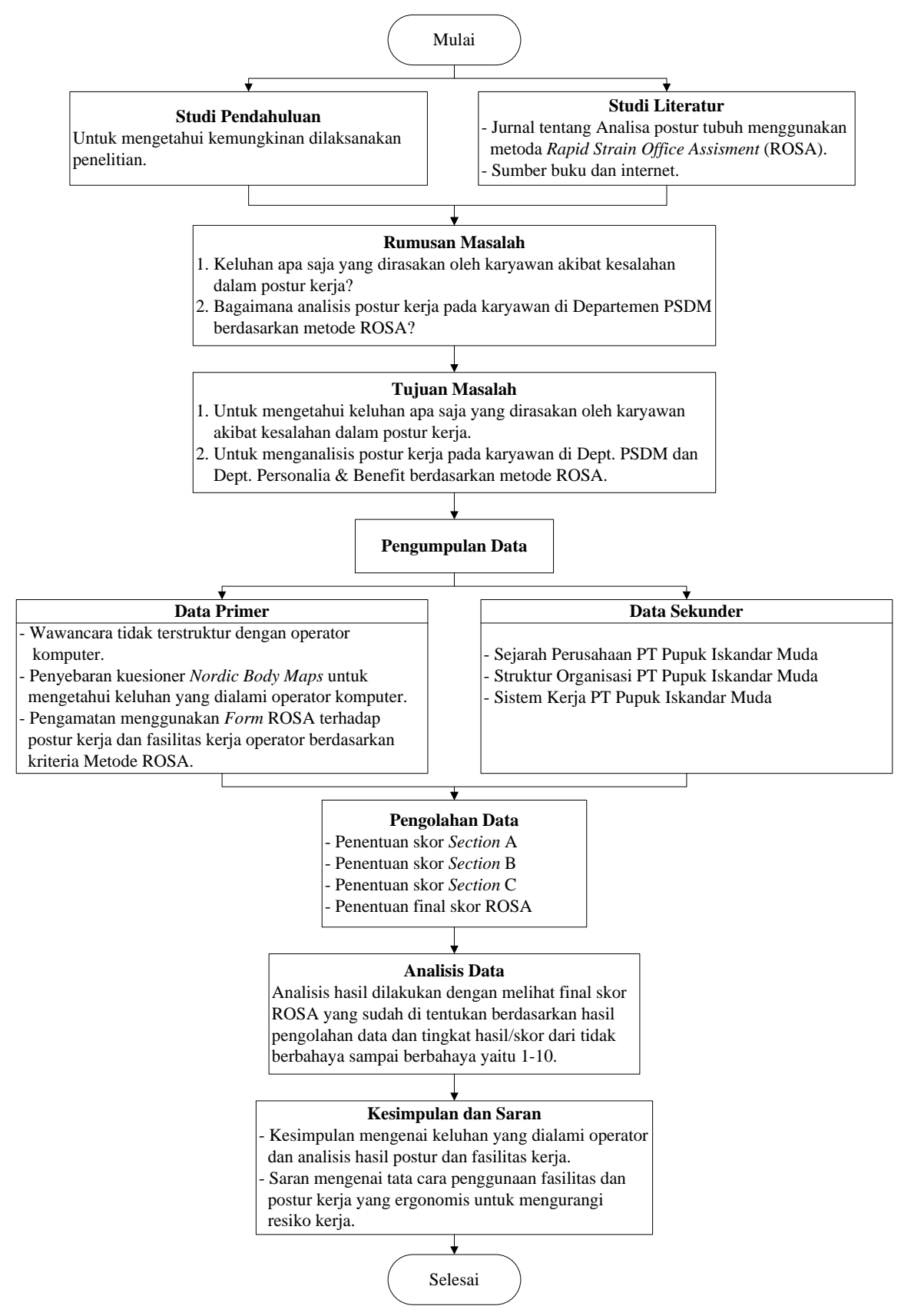

Gambar 1. Flowchart Penelitian

Objek penelitian yang digunakan dalam penelitian ini adalah postur kerja dari 10 karyawan yang menggunakan komputer pada Dept. PSDM dan Dept. Personalia Benefit. Jenis-jenis postur kerja yang diteliti berdasarkan tinggi kursi, lebar dudukan, sandaran lengan, sandaran punggung, ketinggian dan jarak monitor serta mouse dan keyboard.

$\begin{array}{ll}\text { Nama } & : \text { Nanda TRS } \\ \text { Umur } & : \text { 25 Tahun } \\ \text { Departemen } & : \text { Pengembangan SDM } \\ \text { Lama Jam Bekerja } & : \pm 8 \text { Jam/Hari } \\ \text { Masa Kerja } & : \text { 1 Tahun 4 Bulan }\end{array}$

Adapun pengolahan data yang dilakukan dari data yang telah dikumpulkan berdasarkan pengamatan adalah: 1. Penilaian skor terhadap postur tubuh Section A. 
2. Penilaian skor terhadap postur tubuh Section B.

3. Penilaian skor terhadap postur tubuh Section C.

Nilai skor Section A,B dan C kemudian ditambah dengan nilai skor durasi untuk mendapatkan nilai total skor kursi. Adapun ketentuan nilai skor durasi sebagai berikut:

1. Jika bekerja terus menerus dilaksanakan kurang dari 30 menit atau kurang dari satu jam/hari maka skor total section $\mathrm{A}, \mathrm{B}, \mathrm{C}-1$.

2. Jika bekerja terus menerus dilaksanakan antara 30 menit -1 jam atau $1-4$ jam dalam sehari, maka skor total section $\mathrm{A}, \mathrm{B}, \mathrm{C}+0$.

3. Jika bekerja secara terus menerus lebih dari 1 jam atau lebih dari 4 jam/hari, maka skor total section $\mathrm{A}+1$.

4. Menentukan Final skor ROSA.

Menentukan tingkat level risiko dengan Metode ROSA dapat dilihat pada Tabel.1 berikut ini:

Tabel.1 Level risiko dengan Metode ROSA

\begin{tabular}{|c|c|}
\hline Skala & Tingkat Risiko \\
\hline $1-5$ & Tidak Berbahaya \\
\hline $6-10$ & Berbahaya \\
\hline
\end{tabular}

Sumber : Sonne et.al, 2012

Analisi pemecahan masalah yang dilakukan antara lain adalah menggunakan metode Rapid Office Strain Assessment (ROSA).

\section{Hasil dan Pembahasan}

\section{A. Hasil Penelitian}

Awal penelitian disebarkan kuesioner Nordic Body Map (NBM) dapat dilihat pada lampiran 2 dengan 27 pertanyaan ditemukan beberapa hasil keluhan sistem otot rangka dan ketidak nyamanan dalam bekerja antara lain agak sakit pada leher bagian atas dan bawah, sakit pada lengan atas kanan dan pergelangan tangan, sakit pada pergelangan tangan kiri dan sakit pada pinggang.

Selanjutnya dilakukan evaluasi postur kerja menggunakan form ROSA berdasarkan objek yang diamati. Pengolahan data dengan penentuan skor pada bagian A, penentuan skor bagian B, penentuan skor bagian $C$ dan penentuan nilai akhir. Adapun pengolahan data berdasarkan form ROSA dapat dilihat sebagai berikut:

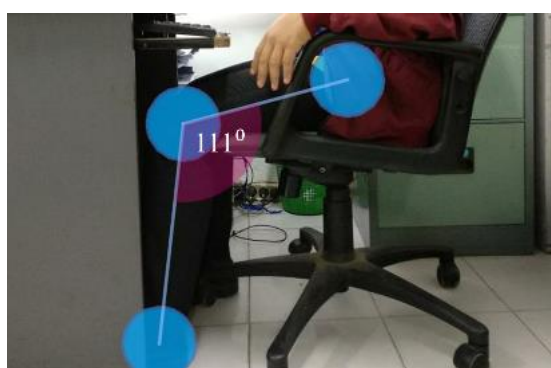

(a)

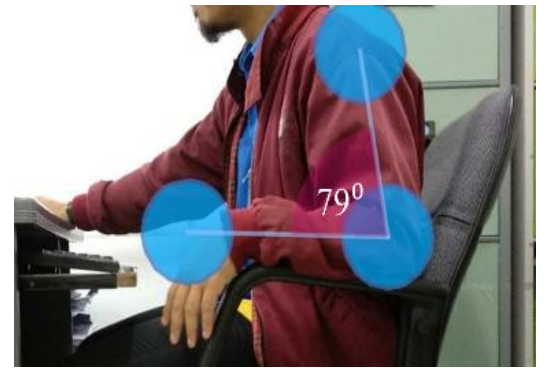

(b)

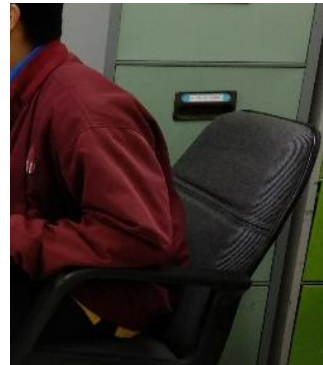

(c)

Gambar.2 Postur Kerja Karyawan 1

(a) Tinggi kursi \& Lebar dudukan (Chair Height \& Pan Depth). (b) Sandaran lengan (Arm Rest). (c) Sandaran punggung (Back Support). 
Form Pengamatan Postur Kerja Karyawan 1

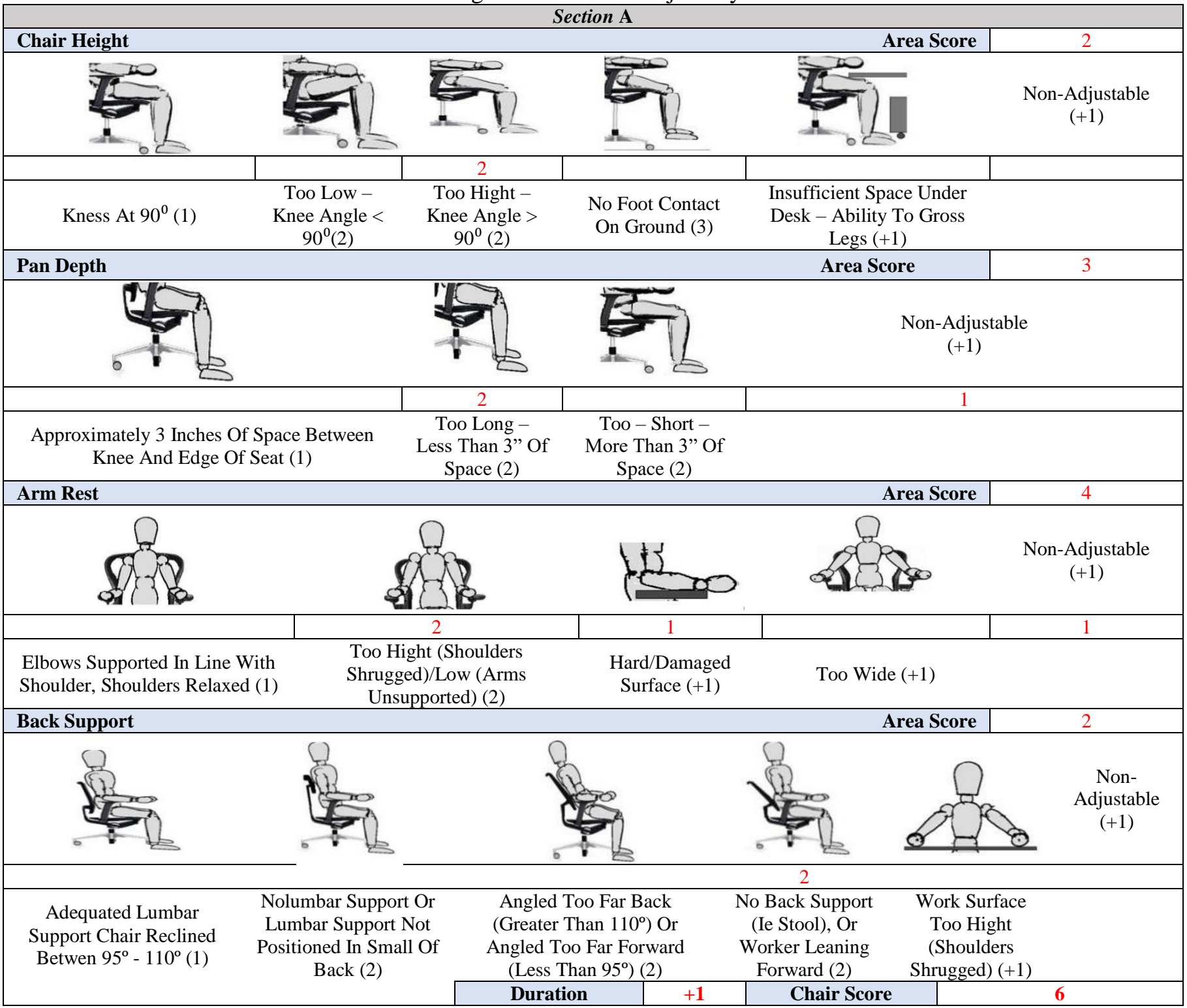

Jadi, skor Section A (Chair Score) adalah Arm Rest + Back Support $4+2=6$, Chair Height + Pan Depth 2 $+3=5$. Perolehan angka tersebut akan digunakan untuk mencari skor kursi secara keseluruhan dengan menggunakan tabel section A + skor durasi.

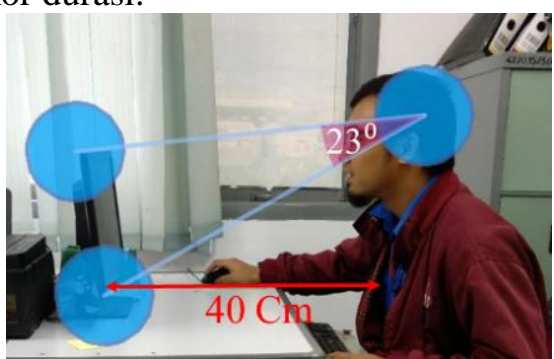

(a)

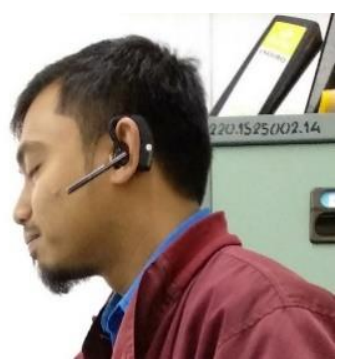

(b)

Gambar.3 Postur Kerja Karyawan 1

(a) Monitor. (b) Telephone 
Form Pengamatan Postur Kerja Karyawan 1

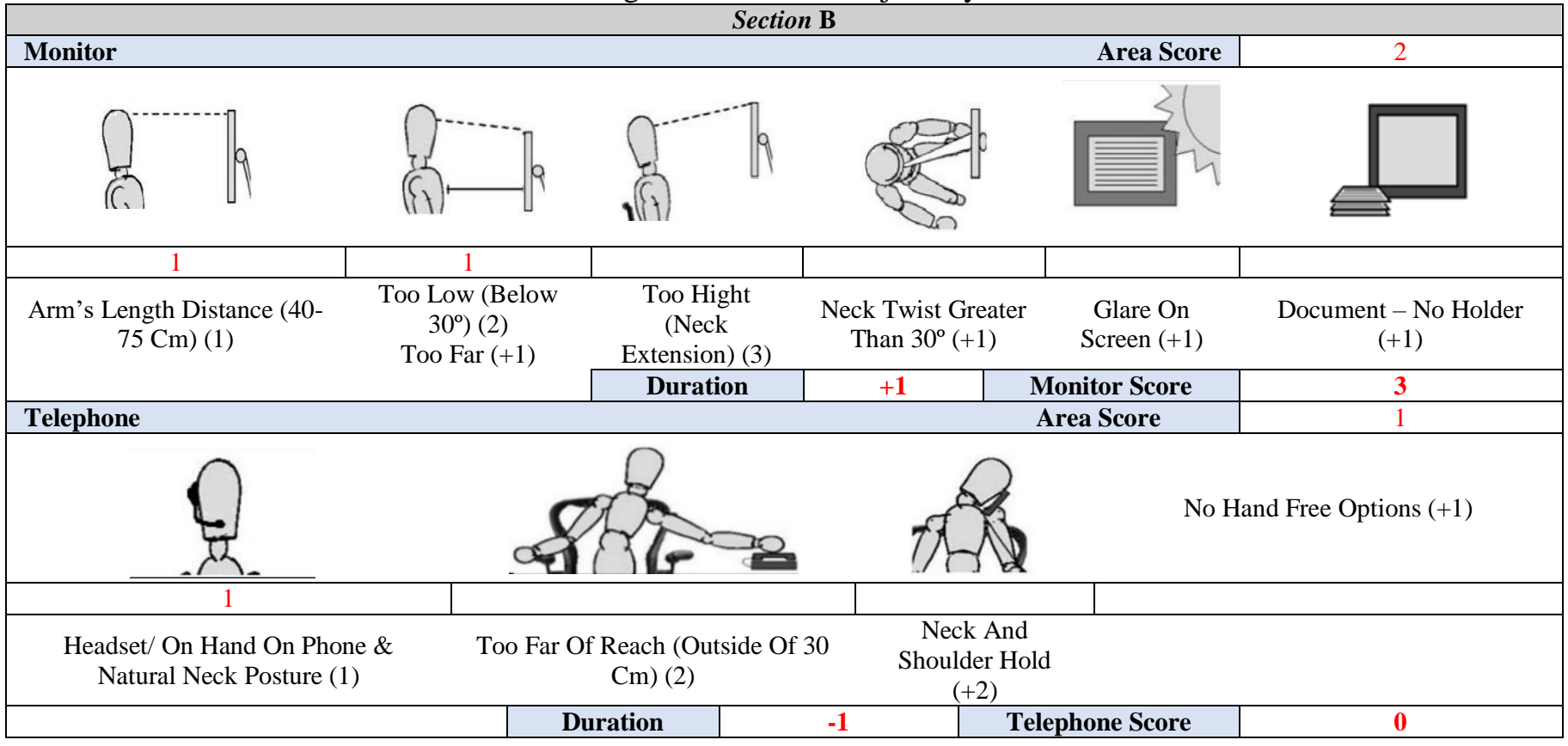

Jadi, skor Section B adalah : Monitor + Durasi $2+1=3$, Telephone - Durasi $1-1=0$. Perolehan angka tersebut akan digunakan untuk mencari skor monitor dan telepon dengan menggunakan tabel section $\mathrm{B}$.

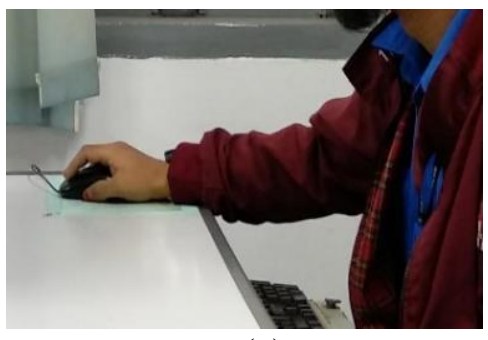

(a)

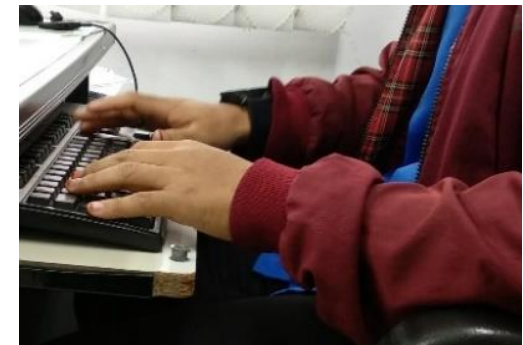

(b)

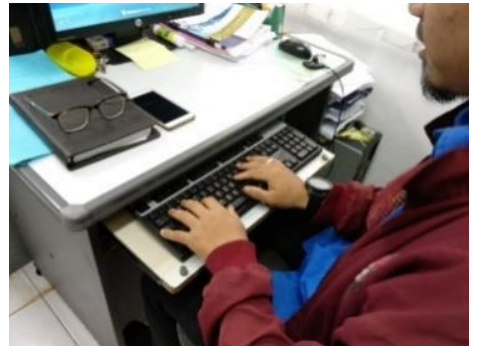

(c)

Gambar.4 Postur Kerja Karyawan 1

(a) Mouse. (b,c) Keyboard. 
Form Pengamatan Postur Kerja Karyawan 1

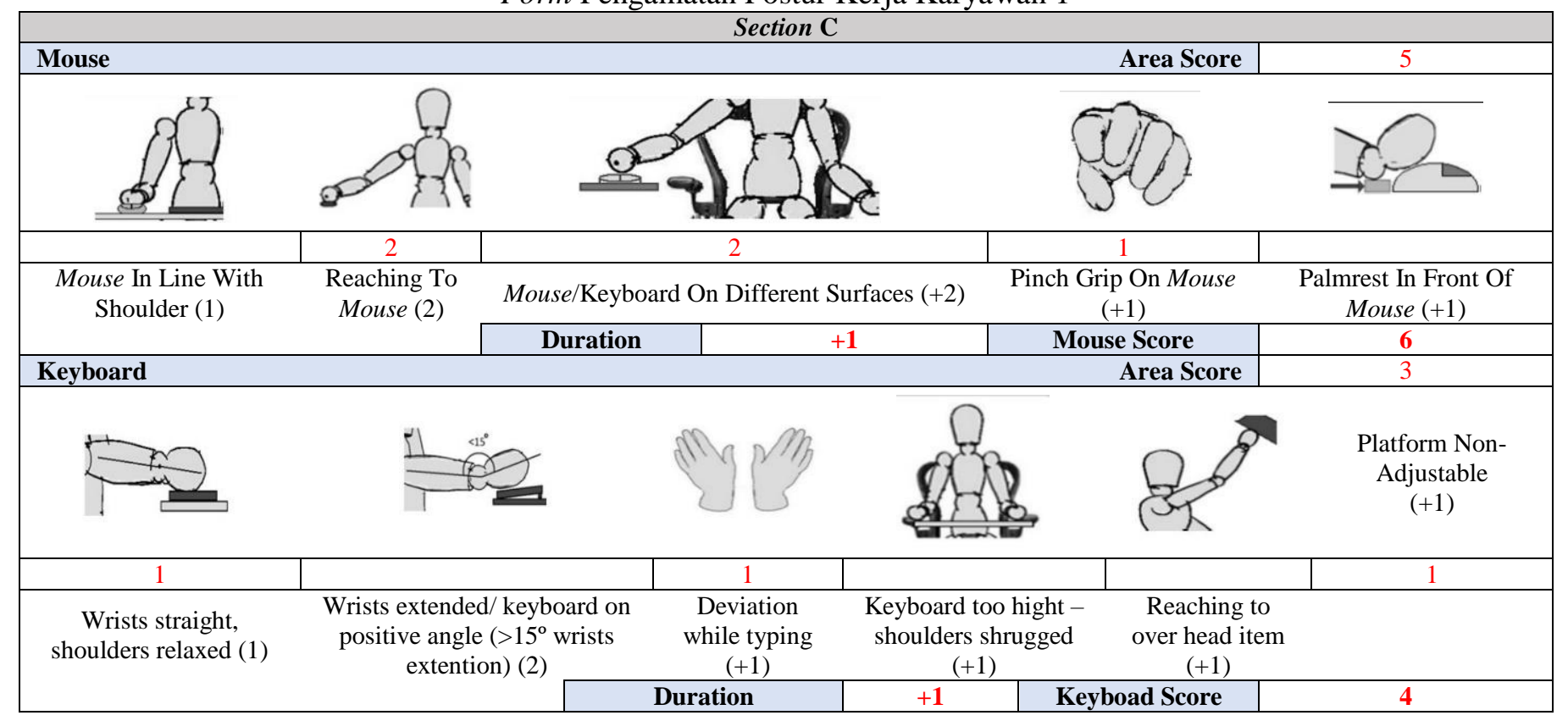

Jadi, skor Section C adalah : Mouse + Durasi $5+1=6$, Keyboard + Durasi $3+1=4$. Perolehan angka tersebut akan digunakan untuk mencari skor monitor dan telepon dengan menggunakan tabel section $\mathrm{C}$.

Final Score ROSA

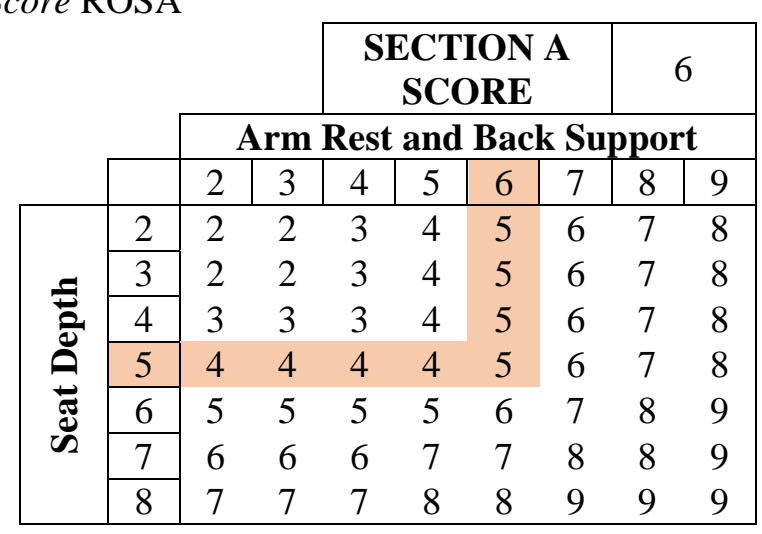

\begin{tabular}{|c|c|c|c|c|c|c|c|c|c|}
\hline & & & & \multicolumn{4}{|c|}{$\begin{array}{l}\text { SECTION B } \\
\text { SCORE }\end{array}$} & \multicolumn{2}{|c|}{2} \\
\hline & & \multicolumn{8}{|c|}{ Monitor } \\
\hline & & 0 & 1 & 2 & 3 & 4 & 5 & 6 & 7 \\
\hline \multirow{7}{*}{$\frac{\mathscr{E}}{\stackrel{\Xi}{\Xi}}$} & 0 & 1 & 1 & 1 & 2 & 3 & 4 & 5 & 6 \\
\hline & 1 & 1 & 1 & 2 & 2 & 3 & 4 & 5 & 6 \\
\hline & 2 & 1 & 2 & 2 & 3 & 3 & 4 & 6 & 7 \\
\hline & 3 & 2 & 2 & 3 & 3 & 4 & 5 & 6 & 8 \\
\hline & 4 & 3 & 3 & 4 & 4 & 5 & 6 & 7 & 8 \\
\hline & 5 & 4 & 4 & 5 & 5 & 6 & 7 & 8 & 9 \\
\hline & 6 & 5 & 5 & 6 & 7 & 8 & 8 & 9 & 9 \\
\hline
\end{tabular}

\begin{tabular}{|c|c|c|c|c|c|c|c|c|c|}
\hline & & & & \multicolumn{4}{|c|}{$\begin{array}{c}\text { SECTION C } \\
\text { SCORE }\end{array}$} & \multicolumn{2}{|c|}{7} \\
\hline & & \multicolumn{8}{|c|}{ Keyboard } \\
\hline & & 0 & 1 & 2 & 3 & 4 & 5 & 6 & 7 \\
\hline \multirow{8}{*}{ है } & 0 & 1 & 1 & 1 & 2 & 3 & 4 & 5 & 6 \\
\hline & 1 & 1 & 1 & 2 & 3 & 4 & 5 & 6 & 7 \\
\hline & 2 & 1 & 2 & 2 & 3 & 4 & 5 & 6 & 7 \\
\hline & 3 & 2 & 3 & 3 & 3 & 5 & 6 & 7 & 8 \\
\hline & 4 & 3 & 4 & 4 & 5 & 5 & 6 & 7 & 8 \\
\hline & 5 & 4 & 5 & 5 & 6 & 6 & 7 & 8 & 9 \\
\hline & 6 & 5 & 6 & 6 & 7 & 7 & 8 & 8 & 9 \\
\hline & 7 & 6 & 7 & 7 & 8 & 8 & 9 & 9 & 9 \\
\hline
\end{tabular}

\begin{tabular}{|c|c|c|c|c|c|c|c|c|c|c|}
\hline & & \multicolumn{7}{|c|}{$\begin{array}{c}\text { MONITOR AND } \\
\text { PERIPHERALS SCORE } \\
\end{array}$} & \multicolumn{2}{|c|}{7} \\
\hline & & \multicolumn{9}{|c|}{ Mouse \& Keyboard } \\
\hline & & 1 & 2 & 3 & 4 & 5 & 6 & 7 & 8 & 9 \\
\hline \multirow{9}{*}{ 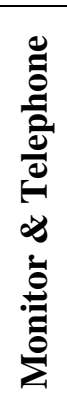 } & 1 & 1 & 2 & 3 & 4 & 5 & 6 & 7 & 8 & 9 \\
\hline & 2 & 2 & 2 & 3 & 4 & 5 & 6 & 7 & 8 & 9 \\
\hline & 3 & 3 & 3 & 3 & 4 & 5 & 6 & 7 & 8 & 9 \\
\hline & 4 & 4 & 4 & 4 & 4 & 5 & 6 & 7 & 8 & 9 \\
\hline & 5 & 5 & 5 & 5 & 5 & 5 & 6 & 7 & 8 & 9 \\
\hline & 6 & 6 & 6 & 6 & 6 & 6 & 6 & 7 & 8 & 9 \\
\hline & 7 & 7 & 7 & 7 & 7 & 7 & 7 & 7 & 8 & 9 \\
\hline & 8 & 8 & 8 & 8 & 8 & 8 & 8 & 8 & 8 & 9 \\
\hline & 9 & 9 & 9 & 9 & 9 & 9 & 9 & 9 & 9 & 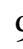 \\
\hline
\end{tabular}




\begin{tabular}{|c|c|c|c|c|c|c|c|c|c|c|c|}
\hline & & \multicolumn{10}{|c|}{ Peripherals and Monitor } \\
\hline & & 1 & 2 & 3 & 4 & 5 & 6 & 7 & 8 & 9 & 10 \\
\hline \multirow{10}{*}{ } & 1 & 1 & 2 & 3 & 4 & 5 & 6 & 7 & 8 & 9 & 10 \\
\hline & 2 & 2 & 2 & 3 & 4 & 5 & 6 & 7 & 8 & 9 & 10 \\
\hline & 3 & 3 & 3 & 3 & 4 & 5 & 6 & 7 & 8 & 9 & 10 \\
\hline & 4 & 4 & 4 & 4 & 4 & 5 & 6 & 7 & 8 & 9 & 10 \\
\hline & 5 & 5 & 5 & 5 & 5 & 5 & 6 & 7 & 8 & 9 & 10 \\
\hline & 6 & 6 & 6 & 6 & 6 & 6 & 6 & 7 & 8 & 9 & 10 \\
\hline & 7 & 7 & 7 & 7 & 7 & 7 & 7 & 7 & 8 & 9 & 10 \\
\hline & 8 & 8 & 8 & 8 & 8 & 8 & 8 & 8 & 8 & 9 & 10 \\
\hline & 9 & 9 & 9 & 9 & 9 & 9 & 9 & 9 & 9 & 9 & 10 \\
\hline & 10 & 10 & 10 & 10 & 10 & 10 & 10 & 10 & 10 & 10 & 10 \\
\hline & & & & & & & \multicolumn{3}{|c|}{$\begin{array}{c}\text { FINAL SCORE } \\
\text { ROSA }\end{array}$} & \multicolumn{2}{|c|}{7} \\
\hline
\end{tabular}

Cara yang sama dilakukan pada karyawan 1 sampai dengan karyawan ke 10.Adapun rekapitulasi final skor ROSA dapat dilihat pada Tabel.2 di bawah ini:

Tabel.2 Final Score Metode ROSA

\begin{tabular}{|c|c|c|c|}
\hline No & Bagian & Nilai & Risiko \\
\hline 1 & Karyawan 1 & 7 & Berbahaya \\
\hline 2 & Karyawan 2 & 7 & Berbahaya \\
\hline 3 & Karyawan 3 & 7 & Berbahaya \\
\hline 4 & Karyawan 4 & 7 & Berbahaya \\
\hline 5 & Karyawan 5 & 8 & Berbahaya \\
\hline 6 & Karyawan 6 & 6 & Berbahaya \\
\hline 7 & Karyawan 7 & 6 & Berbahaya \\
\hline 8 & Karyawan 8 & 7 & Berbahaya \\
\hline 9 & Karyawan 9 & 7 & Berbahaya \\
\hline 10 & Karyawan 10 & 6 & Berbahaya \\
\hline
\end{tabular}

Berdasarkan dari nilai final skor yang didapat keseluruh karyawan memiliki tingkat risiko berbahaya karena memiliki nilai lebih dari 5. Sehingga perlu dilakukan penanganan dalam waktu dekat.

\section{B. Analsis Penyebab Masalah}

Setelah mengetahui nilai akhir dari tingkat keamanan pekerja, selanjutnya adalah mengidentifikasi penyebab masalah. Identifikasi masalah bertujuan untuk mengurangi risiko yang dirasakan oleh pekerja. Tingginya nilai risiko disebabkan oleh dua faktor utama yaitu fasilitas yang kurang mendukung dan kurangnya kesadaran pada pekerja tentang penggunaan fasilitas dengan benar.

Pada ketinggian kursi 9 dari 10 kursi karyawan sudah memadai untuk digunakan pada saat pekerja, namun masih terdapat 1 kursi karyawan yang tidak dapat diatur ketinggiannya yaitu karyawan 3. Ketinggian kursi yang tidak dapat diatur dapat menyebabkan sudut yang dibentuk oleh lutut kurang dari $90^{\circ}$. Adapun karyawan yang memiliki kursi dapat yang dapat diatur ketinggiannya tetapi memilih duduk dengan posisi lutut lebih besar atau lebih kecil dari $90^{\circ}$. Karyawan yang tidak mengetahui risiko dari pengaturan kursi menjadi faktor penyebab tingginya risiko pada ketinggian kursi serta lebarnya dudukan kursi yang tidak dapat diatur sehingga menyebabkan kaki pekerja tidak menapak seluruhnya ke lantai. 
Pada sandaran tangan terdapat beberapa penyebab yang mempengaruhi risiko yang dirasakan oleh karyawan, salah satunya sandaran lengan tidak dapat diatur pada penggunaannya. Pada karyawan 3 tidak memiliki sandaran lengan dan 9 karyawan lainnya tidak menggunakan sandaran lengan pada saat bekerja serta diantaranya memiliki sandaran lengan yang terlalu tinggi atau rendah. Hal ini menyebabkan tingginya nilai risiko pada sandaran lengan. Penggunaan Meja yang terlalu tinggi sehingga menuntut pekerja untuk tidak menggunakan sandaran lengan pada saat bekerja.

Sandaran punggung dari seluruh kursi yang digunakan karyawan sudah memadai dilihat dari panjang dan lebar kursi dan 9 kursi yang digunakan karyawan dapat diatur pada penggunaannya, tetapi hampir seluruh karyawan tidak menggunakan sandaran punggung pada saat bekerja. Belum adanya kesadaran karyawan dalam menggunakan sandaran punggung merupakan penyebab salah satu tingginya risiko yang akan dialami karyawan.

Pada saat menggunakan monitor hampir keseluruhan karyawan menggunakannya terlalu rendah. Hal ini dikarenakan monitor yang tidak dapat diatur ketinggiannya sesuai dengan ketinggian karyawan. Namun hanya terdapat satu karyawan yang memiliki monitor yang sesuai dengan tingginya yaitu karyawan 4 .

Pada penggunaan mouse seluruh pekerja masih belum baik dalam peletakannya. Seluruh karyawan meletakkan mouse terlalu jauh yaitu jarak antara karyawan dan mouse sepanjang lengan $(40-50 \mathrm{~cm})$ dan ada beberapa karyawan yang meletakkan mouse dan keyboard tidak dalam satu permukaan misalnya peletakan mouse di atas meja sedangkan keyboard menggunakan laci keyboard dibawah meja, sehingga untuk menjangkau mouse mereka harus mendorong masuk laci keyboard terlebih dahulu.

Tingginya nilai pada penggunaan keyboard disebabkan karena kurangnya kesadaran pekerja pada penggunaan keyboard yang benar. Pada karyawan 1, 3, dan 6 peletakan keyboard menggunakan laci yang sejajar dengan sandara lengan sehingga sesuai dengan poisis ergonomis saat bekerja, akan tetapi tidak adanya kesadaran dari karyawan untuk menggunakan sandaran lengan dan keyboard secara bersamaan. Selain itu ada beberapa karyawan memiliki tinggi meja untuk keyboard yang terlalu tinggi sehingga mempengaruhi kenyamanan pekerja pada saat bekerja. Keyboard yang diletakkan sejajar monitor menyebabkan tangan tergantung dan pergelangan tangan menekuk pada saat penggunaan keyboard di karenakan ketinggian dari meja karyawan.

\section{Kesimpulan dan Saran}

Analisis postur kerja dengan metode Rapid Office Strain Assessment (ROSA) menunjukkan bahwa 10 karyawan yang menjadi sampel penelitian memiliki level beresiko dan perlu dilakukan perbaikan dalam waktu dekat. Penyebab dari tingginya nilai resiko yang dialami oleh karyawan yaitu fasilitas yang digunakan oleh karyawan kurang mendukung dan kurangnya kesadaran karyawan dalam penggunaan fasilitas yang sudah ada serta kurangnya kesadaran karyawan terhadap pentingnya penerapan ergonomi pada dunia kerja, kemudian lamanya bekerja dengan posisi yang salah dan lamanya pekerja menggunakan komputer setiap harinya.

Perbaikan yang dapat dilakukan untuk mengurangi tingkat resiko yang dirasakan oleh karyawan yaitu dengan perbaikan fasilitas yang digunakan oleh karyawan yang sesuai dengan standar ergonomi pada dunia kerja, dan sebaiknya pekerja melakukan istirahat atau peregangan otot minimal setiap 2 jam sekali. Kurangnya kesadaran karyawan dalam penggunaan fasilitas dengan benar dapat diminimalkan dengan adanya pelatihan atau sosialisasi tentang ergonomi terutama diperkantoran terutama kepada karyawan Dept. Personalia \& Benefit dan Dept. Pengembangan SDM. Sosialisasi dilakukan agar karyawan dapat menggunakan fasilitas dengan maksimal.

\section{Referensi}

[1] Anggawisastra, R., Sutalaksana, I. Z, dan Tjakraatmadja, J. H. 1979. Teknik Tata Cara Kerja. Departemen Teknik Industri ITB : Bandung.

[2] Anies. 2005. Penyakit Akibat Kerja. Jakarta : PT. Elex Media Komputindo.

[3] Kroemer, Karl H. E. 2001. (Dalam Jurnal Damayanti. Dkk). Office Ergonomic. USA: CRC Press.

[4] Nurmianto, Eko. 1996. Ergonomi : Konsep Dasar dan Aplikasinya. Surabaya : Guna Wijaya.

[5] Ontario. 2004.Computer Ergonomics: Workstasion Layout and Lighting. Canada : Profesional and Spesialized Service Minstry of Labour.

[6] Ramadhani, Merulla. 2010. Postur Tubuh Yang Ergonomis Saat Bekerja. Agustus 30. Akses 24 Oktober 2018. Web. http://merulalia.wordpress.com/2010/08/30/postur-tubuh-yang-ergonomis-saat-bekerja/.

[7] Sonne, M. Villalta, D. L. And Andrew, D. M. 2012. Development and Evaluation of an Office Ergonomic Risk Cheecklist: ROSA-Rapid Offeice Strain Assessment. Applied Ergonomic. Vol. 43, No. 1, (2012), 98-108.

[8] Tarwaka. 2004. Keselamatan dan Kesehatan Kerja. Manajemen dan Implmentasi K3 di Tempat Kerja. Surakarta : Harapan Press. 